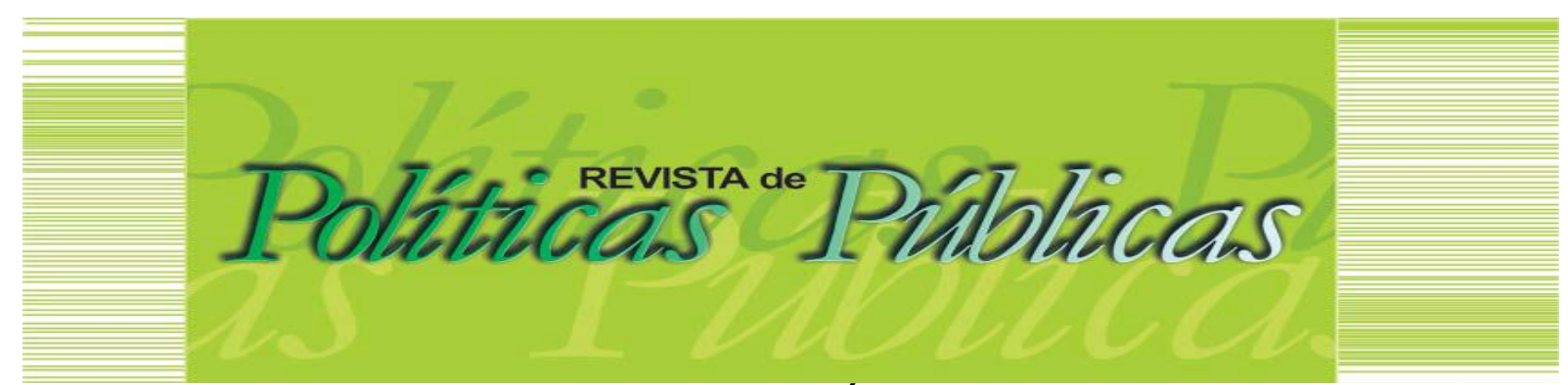

\title{
A PASSIVIDADE ESTRATEGICAMENTE CONSTRUÍDA: o consenso contemporâneo a partir de categorias gramscianas
}

\section{Resumo}

O objetivo deste artigo é analisar a expansão da dominação capitalista e avanço do conservadorismo em busca de hegemonia exercida por meio da construção de passividade, via implementação de políticas sociais focalizadas e compensatórias para atender as exigências das classes subalternas por meio de consenso e do estabelecimento de estratégias de contenção da luta de classes. Nesse sentido, os procedimentos teóricos utilizados foram a análise bibliográfica das categorias gramscianas expostas nos cadernos do cárcere. 0 artigo aponta, ainda, elementos que merecem aprofundamento para estabelecimento de uma urgente reforma intelectual e moral das massas como expressão de resistência, tendo em vista a expansão da dominação burguesa com consensos que dissipam a construção de um projeto alternativo para os trabalhadores, com retrocesso de conhecimento, e, principalmente, de lutas.

Palavras chaves: Passividade. Lutas de Classes. Hegemonia. Consenso.

\section{THE STRATEGICALLY CONSTRUCTED PASSIVITY: the contemporary consensus from Gramscian categories}

\begin{abstract}
The objective of this article is to analyze the expansion of capitalist domination and the advance of conservatism in search of hegemony exercised through the construction of passivity, through the implementation of social policies focused and compensatory to meet the demands of the subaltern classes, through consensus and establishment strategies of contention of the class struggle. In this sense, the theoretical procedures used were the bibliographical analysis of the Gramscian categories exposed in the notebooks of the jail. It points out elements that merit deepening to establish an urgent intellectual and moral reform of the masses as an expression of resistance, in view of the expansion of bourgeois domination with consensuses that dissipate the construction of an alternative project for the workers. With retreat of knowledge, and, mainly, of fights.

Keywords: Passivity. Class Struggles. Hegemony. Consensus.
\end{abstract}

Artigo recebido em: 10/04/2020 Aprovado em: 13/10/2020 DOI: http://dx.doi.org/10.18764/2178-2865.v24n2p769-781.

\footnotetext{
${ }^{1}$ Assistente Social. Mestra em Serviço Social pela Universidade Federal de Pernambuco.. Pesquisadora CNPQ. Participa do Núcleo de Estudos e Pesquisas Ações em Rede Coordenadas no Universo Social - ARCUS - UFPE. E-mail: josinetecarvalhobezerra@gmail.com
} 


\section{INTRODUÇÃO}

O presente artigo trata-se de uma pesquisa bibliográfica, que objetiva analisar a expansão da dominação capitalista em busca de hegemonia, exercida principalmente, mas, não somente, por meio da implementação de políticas sociais focalizadas e compensatórias para atender as exigências das classes subalternas consolidando um consenso e o estabelecimento de estratégias de contenção da luta de classes.

Com a temática, procura-se debater o papel exercido pelas políticas sociais implementadas pelo aparelho estatal desde a nossa formação histórica, social e política para atender as exigências das classes subalternas, sendo estas, intensificadas na contemporaneidade para manter um consenso entre as classes antagônicas e a hegemonia dos dominantes sobre os dominados.

Diante das mudanças no mundo do trabalho, das necessidades sociais dos sujeitos e avanço do modo de produção capitalista, permanecem relações sociais constituídas por exploração, alienação e antagonismos entre as classes. Neste sentido, o desenvolvimento das políticas sociais tem sido cada vez mais necessário, como principal meio de enfrentamento das desigualdades postas, mas, e contraditoriamente, sendo estas constantemente apropriadas para favorecer, também, senão primordialmente, o grande capital. Assim sendo, discute-se inicialmente o desenvolvimento e particularidade das políticas sociais na contemporaneidade e momentos de "passividade" 1 da classe trabalhadora.

Destarte, acompanha-se um desmonte da Seguridade Social com impactos na proteção social e regressão de direitos, visto que o governo federal desenvolve cortes nos beneficiários de programas sociais, embora, por outro lado, anuncie a implementação de reajuste nos programas de transferência de renda, ressaltando-se aqui, o Programa Bolsa Família. Tal contexto repercute em efeitos contraditórios no tocante à melhoria das condiçoes de vida das famílias que se encontram em situação de vulnerabilidade, ocorrendo assim, mistificação, um determinado conformismo e consolidação do consenso. Devido a isso, posteriormente analisa-se o desenvolvimento contemporâneo da hegemonia, consenso e a dominação sobre as classes subalternas.

Nesse sentido, as contradições inerentes ao sistema capitalista trazem novas roupagens ao modo de organização social, onde a classe dominante preocupa-se em conservar o ciclo do capital e aumento do lucro, subordinando a classe trabalhadora na sua produção e reprodução de forma alienada.

Foi nesse contexto que as políticas sociais referentes ao tripé da Seguridade Social passaram a ser estrategicamente intensificadas, não como uma resposta conscienciosa às 
necessidades sociais, mas como uma via de reaproximação do Estado com a sociedade, devido ao desmonte dos direitos sociais, ao desemprego e ao combate a todos os impactos da nova organização do mundo do trabalho. Porém, com a instalação do golpe de 2016 a realidade aprofunda-se ainda mais com cortes e regressos nos direitos sociais e trabalhistas.

A classe dominante, ciente da necessidade de estabelecer consenso com as classes subalternas para manter sua dominação, apropria-se das políticas sociais com intuito de atender reivindicações das massas por meio de respostas paliativas que não têm capacidade de transformar a realidade, e que, principalmente, não alteram o modo de produção capitalista, responsável maior pela desigualdade social. Neste sentido, apenas fortalece a hegemonia burguesa, e ainda imobiliza as reivindicações. Por fim, será então, identificada a emergência da reforma intelectual e moral das massas para enfrentamento da realidade posta, tendo em vista a necessidade de fortalecimento e resgate de instrumento de luta e defesa da "classe que vive do trabalho".

Portanto, diante dessas configurações que impactam os direitos sociais e trabalhistas conquistados e mistifica uma realidade cada vez mais desigual, dificultando assim, o desvelamento das contradições, torna-se urgente a necessidade de estabelecimento de novas formas de estratégias de luta e resistência para superação de lapsos de passividade, visando estabelecer análises e posicionamentos de forma crítica.

\section{DESENVOLVIMENTO E PARTICULARIDADE DAS POLÍTICAS SOCIAIS NA CONTEMPORANEIDADE: a "passividade" da classe trabalhadora}

As políticas sociais ora podem ser analisadas como forma de estratégias, ora como direitos, visto que, respectivamente, atendem necessidades sociais e necessidades do capital, tendo em vista as relações sociais contraditórias e seus interesses antagônicos estabelecidos no Estado capitalista, que tem como fundamental a busca do lucro, mistificando um contexto social de exploração, permanecendo indivíduos detentores de poder e outros subordinados a eles, havendo assim, uma desigualdade entre as classes.

Nesse sentido, as políticas sociais emergem para responder determinadas exigências sociais, mas atendendo, também, necessidades capitalistas. Portanto, é imprescindível uma mediação, pois, diante do capitalismo, tais políticas são necessárias para amenizar as contradições existentes na relação capital/trabalho, caracterizando uma interdependência entre eles. Ou seja, as relações sociais são também relações capitalistas que geram problemas sociais, precisando ser tratados de forma politizada. 
Com isso,

[...] é interessante notar que a criação dos direitos sociais no Brasil resulta da luta de classes e expressa a correlação de forças predominante. Por um lado, os direitos sociais, sobretudo trabalhistas e previdenciários, são pauta de reivindicação dos movimentos e manifestações da classe trabalhadora. Por outro representam a busca da legitimidade das classes dominantes em ambiente de restrição de direitos políticos e civis (BEHRING; BOSCHETTI, 2011, p.78).

As políticas sociais são respostas dadas ás refrações da questão social; surgem, então, para atender suas demandas, mas, analisando a formação social, histórica e política do nosso país, verifica-se que estas foram estabelecidas somente após reivindicações organizadas pelos trabalhadores, quando o Estado é convocado a intervir nas relações sociais atendendo a população. Todavia, um longo caminho de lutas foi percorrido para chegar a esse ponto.

"O surgimento das políticas sociais foi gradual e diferenciado entre os países" (BEHRING \& BOSCHETTI, 2011, p.64). No Brasil, elas se desenvolveram de forma distinta dos países do capitalismo central, pois o mesmo foi marcado pela dependência e subdesenvolvimento, mas, mantiveram-se suas características essenciais. Não havia preocupações com os problemas que já assolavam aquela sociedade, e sim com a busca da acumulação. Esta relação acarreta sérios impactos ao desenvolvimento dos direitos sociais.

Dessa forma, a particularidade mais comum no desenvolvimento de políticas sociais, independente do país em que são formuladas, é que emergem no cerne de um conflito econômicopolítico e social em que as contradições sociais se avolumam ao ponto de gerarem uma mudança na estratégia adotada pelos governos com intuito principal de manterem a sua governabilidade².

Durante o mais longo período de poder de um partido eleito democraticamente no Brasil, 13 anos e 132 dias, o então denominado Partido dos Trabalhadores, esta realidade foi visível. Luiz Inácio Lula da Silva e Dilma Roussef eram identificados como um governo populista; ambos traziam uma determinada esperança para a população e, por meio de medidas paliativas atenderam demandas dos mais pobres, beneficiando porém, por outro lado, os mais ricos ${ }^{3}$.

Assim, o governo do PT, diante da expansão do seu mandato, conseguiu estabelecer um consenso ora ativo, ora passivo ${ }^{4}$ com a população.

O consenso é ativo quando os governados participam da vida do organismo estatal em cuja condição há governos aceitos por aqueles. 0 consenso é passivo quando os governados subscrevem com atos formalmente democráticos (o sufrágio) a aceitação daqueles que os guiam e que, por isso, numa perspectiva de democracia formal, tendencialmente os dominam (LIGUORI; VOZA, 2017, p.143). 
Durante o longo período no poder, é verificável que o governo petista soube executar seu papel de classe dirigente obtendo o consentimento de grande parte dos sujeitos. Todavia, a partir de 2016, com a insatisfação de determinadas classes e a defesa de "eliminar a corrupção", acompanharam-se manifestações contra a então presidente Dilma Roussef, que é então, afastada do cargo por meio de um impeachment ou golpe político. E, é perante esta realidade de crise orgânica, e, portanto, rompimento de consens $0^{5}$, que a passividade da classe trabalhadora é estratégica, contraditória e paulatinamente intensificada. Ao discutir crise orgânica, Gramsci (2007, p.60) discorre:

[...] Em certo ponto de sua vida histórica, os grupos sociais se separam de seus partidos tradicionais, isto é, os partidos tradicionais naquela dada forma organizativa, com aqueles determinados homens que o constituem, representam e dirigem, não são mais reconhecidos como sua expressão por sua classe ou fração de classe. Quando se verificam estas crises, a situação imediata torna-se delicada e perigosa, pois abre-se o campo às soluções de força, à atividade de potências ocultas representadas pelos homens providenciais ou carismáticos $[\ldots]$

Como vemos, a derrocada do governo foi composta por diversas contradições, todavia destacam-se, nesta conjuntura, as reivindicações organizadas que eram executadas por grande parte da população, ora insatisfeita com a realidade posta, e com tal governo, exigindo assim, a saída da presidenta, ora contra o impechament da Dilma Roussef. Ou seja, como de praxe, a sociedade dividida com o "culto ao personalismo", ainda presente. E, de fato, as respostas oriundas do aparelho estatal caracterizavam-se por força e repressão.

Assim sendo, as responsabilidades de enfrentamento diante de tal crise constituem-se, então, em desafios específicos de cada momento histórico e das lutas estabelecidas. "O processo é diferente em cada país, embora o conteúdo seja o mesmo." (GRAMSCI, 2007, p.60). Mas, com a instalação do golpe, Michel Temer, atual vice-presidente, assume a presidência no ano de 2016, instaura e legitima paulatinamente a regressão dos direitos, que, ressalta-se, já vinha sendo planejada e realizada homeopaticamente em governos anteriores. Concretiza-se, então, a crise orgânica, pois passou a constituir-se num governo dominante, mas, não dirigente, tendo em vista a insatisfação da maioria da população.

Com o novo governo no poder, são consolidadas medidas que já vinham sendo planejadas, compostas de ataques aos direitos da classe trabalhadora. Há uma regressão das conquistas alcançadas após árduas lutas, pois, contemporaneamente, as políticas voltam-se ao assistencialismo e filantropia, sendo constituídas por meio de um retorno ao conservadorismo; sofrem, portanto, cortes drásticos e privatizações. O Estado classista criminaliza os movimentos sociais e culpabiliza os sujeitos, ora através da coerção quando a classe ousa rebelar-se; ora utilizando o consenso $0^{6}$ quando a classe coopera. 
Parece-me que o que de mais sensato e concreto se pode dizer a propósito do Estado ético e de cultura é o seguinte: todo Estado é ético na medida em que uma de suas funções mais importantes é elevar a grande massa da população a um determinado nível cultural e moral, nível (ou tipo) que corresponde às necessidades de desenvolvimento das forças produtivas e, portanto, aos interesses das classes dominantes (GRAMSCI, Q.8, § 179, 2007, p.284).

Nesse sentido, enfatiza-se o importante papel exercido pelo aparelho estatal para atender os interesses da classe dominante, impactando a classe ora dominada. O Estado tem por finalidade atender o mercado e os trabalhadores de forma contraditória e em beneficio do capital. Assim, a classe detentora do poder estabelece caminho para maior legitimação sobre os dominados.

Dessa forma, as políticas sociais contemporâneas são fortemente atingidas, cortes drásticos são implantados com o discurso da retomada do crescimento econômico, a proteção social é desmontada, os direitos perdem seu teor de sociais, pois, prevalece a defesa do individuo, o poder dos dominantes e a dominação sobre os subalternos, como se analisa posteriormente.

3 AVANÇO DO CONSERVADORISMO: hegemonia, consenso e a dominação sobre as classes subalternas

Diante da realidade contemporânea, acompanha-se o desenvolvimento de uma crise econômica e política, e, por outro lado, desmonte e eliminação de direitos sociais e trabalhistas por meio das reformas contemporâneas, com a ideia mistificadora de reerguer o País, caracterizada com a disseminação de ideários conservadores. Assim, analisadas por Oliveira (2010, p.35):

\footnotetext{
Estamos diante da tentativa de modificar o significado da palavra "reforma": o que antes da onda neoliberal queria dizer ampliação dos direitos, proteção social, controle e limitação do mercado etc. significa agora cortes, restrições, supressão desses direitos e desse controle. Estamos diante de uma operação de mistificação ideológica que, infelizmente, tem sido em grande medida bem-sucedida.
}

A classe trabalhadora, cada vez mais heterogênea, ainda enfrenta o crescente processo de desemprego, precarização e terceirização, enquanto "[...] as noções de proteção social apontam para a existência de uma proteção cujo objetivo é lidar com um conjunto estreito de problemas econômicos ou choques de subsistência, ou seja, proteger os indivíduos dos riscos inerentes ao sustento" (COSTA, 2017, p.689). Esse contexto de intensos retrocessos dificulta, e, por vezes, impossibilita o desenvolvimento das lutas de classes; neste sentido, enfatiza-se que este cenário foi e vem sendo estrategicamente construído pela classe detentora dos meios de produção.

O capital juntamente com o Estado conseguiu estabelecer estratégias que enfraqueceram as reivindicações e organizações das lutas proletárias, as inserções no mercado de trabalho são 
precárias e diversificadas, o exército de reserva é cada vez mais ampliado; verifica-se ainda, dificuldade para que os indivíduos se reconheçam enquanto classe trabalhadora. A passagem da classe em si à classe para si, debatido por Marx (1982, p.159), parece retroceder novamente no seu real sentido. "[...] Esta massa, pois, é já, face ao capital, uma classe, mas ainda não o é para si mesma. Os interesses que defende se tornam interesses de classe. Mas a luta entre classes é uma luta política."

Nesse sentido, o desenvolvimento da hegemonia da classe dominante e o avanço do conservadorismo expandem-se pela sociedade. Estado e capital, cada vez mais unidos para ampliar o poder econômico e político sobre os trabalhadores, de uma forma estratégica e mistificadora, com intuito de que, de alguma maneira os subalternos aparentem ter algum benefício. mesmo que ínfimo.. Ao debater sobre hegemonia Gramsci $(2007$, p.48), brilhantemente enfatiza:

[...] O fato da hegemonia pressupõe indubitavelmente que sejam levados em conta os interesses e as tendências dos grupos sobre os quais a hegemonia será exercida, que se forme certo equilíbrio de compromisso, isto é, que o grupo dirigente faça sacrifícios de ordem econômico-corporativa, mas também é indubitável que tais sacrifícios e tal compromisso não podem envolver o essencial, dado que, se a hegemonia é ético-política, não pode deixar de ser também econômica, não pode deixar de ter seu fundamento na função decisiva que 0 grupo dirigente exerce no núcleo decisivo da atividade econômica.

Portanto, diante das novas reconfigurações impostas paulatinamente pela burguesia, é possível verificar expansão da dominação sobre as classes subalternas, por meio do estabelecimento de consenso/coerção. Todavia, concomitante a isto, prevalece o crescimento da pobreza e desigualdade social. Afinal, para o desenvolvimento da lei geral da acumulação capitalista, quanto mais pobres os trabalhadores, mais ricos serão os capitalistas.

Ao analisar tal conjuntura, enfatiza-se o papel que vem sendo exercido pelas políticas sociais, visto que permanece e amplia-se a agudização das expressões da questão social; logo, suas formas de enfrentamento também têm sido ressaltadas. Entretanto, lanni, desde (1996), já mencionava duas explicações que naturalizam a questão social: uma que tende a transformar manifestações da questão social em problemas da assistência social, e outra que tende a transformá-las em problema de violência ou caos. A resposta seria então: segurança e repressão. Pensamento ainda bastante atual em nossa sociedade diante do desenvolvimento de ideias conservadoras.

Nesse sentido, a política pública de assistência social exerce funções que necessitam ser analisadas criticamente. A assistência social torna-se cada vez mais imprescindível para enfrentamento da realidade posta, com 0 intuito de enfrentamento da pobreza e desigualdade social. Todavia, a 
mesma exerce estrategicamente, por meio do atendimento de quem dela necessita, um determinado consenso e possível apassivamento das classes subalternas.

As políticas sociais são estrategicamente desenvolvidas, mas, também necessárias, pois se constituem como direitos, daí sua contradição ora como direito, ora como estratégia, portanto, contribuindo para o desenvolvimento da passividade das classes subalternas e, assim sendo, para a consolidação da hegemonia dos dominantes. "Enquanto a economia cresce e o poder estatal se fortalece, a massa de trabalhadores padece" (IANNI, 1996, p. 146).

As estratégias desenvolvidas pela classe detentora do poder são construídas social e contraditoriamente, com 0 intuito de mistificar o seu papel enquanto agente de retenção de direitos sociais e trabalhistas e para fortalecer a economia capitalista. Ao mesmo tempo amortecem as lutas das classes trabalhadoras, ainda identificadas por vários autores como a principal, senão, única possibilidade de enfrentamento das opressões capitalistas, como se discute posteriormente. Há, portanto, um longo caminho a ser percorrido.

4 A LUTA DE CLASSE COMO PONTO DE PARTIDA: emergência da reforma intelectual e moral das massas como forma de resistência

Como analisado anteriormente, deve-se observar uma conjuntura perversa para a "classe que vive do trabalho". Nos últimos anos foram intensificados contextos de contrarreformas e cortes drásticos nos direitos e políticas sociais que eliminam direitos imprescindíveis para os trabalhadores.

Diante dessa realidade do retrocesso de direitos sociais e trabalhistas, é assustadora a forma como a sociedade acompanha, quase que paralisada, a derrocada de lutas importantes e conquistas que já estavam decretadas por leis. Nas palavras de lasi (2012, p. 285):

O capital cumpriu sua tarefa, mundializou-se, monopolizou-se, estendeu suas garras dissolvendo as mais ternas ilusões românticas no frio cálculo egoísta, subordinou o campo à cidade, a ciência à indústria, a estética ao mercado, mercantilizou todas as esferas da vida. Na sua forma madura e parasitária, bem diversa daquela pela qual os ideólogos liberais projetavam seus mitos futuros, o capital assume a forma de sua negação tronando-se um enorme entrave à vida humana.

De fato, aparentemente, o capital está consolidando suas estratégias de dominação sobre a classe subalterna, exercendo assim, cortes orçamentários, contrarreformas que alteram e retiram direitos e resgate do conservadorismo. Tudo isso de uma maneira bem construída e projetada de forma a alienar e paralisar os sujeitos sociais. "Diante de tal massacre, estamos no ponto mais agudo de uma 
defensiva da classe trabalhadora que parece respaldar os rumos da ordem capitalista, anestesiada, apassivada. Nada!" (IASI, 2012, p. 286).

Nessa perspectiva, frente a tal imobilidade da classe responsável pela riqueza socialmente produzida, é visível uma população acrítica perante as mudanças que assolam o mundo do trabalho; há instauração de um determinado conformismo e a descrença nas lutas proletárias. $\mathrm{E}$ todo esse contexto foi estrategicamente implantado em nosso meio, num país marcado por processos como dependência, subdesenvolvimento, revoluções pelo alto, culto ao personalismo, corrupção e repressão, visto a necessidade do consentimento entre classes antagônicas ${ }^{7}$, tal realidade é sua principal decorrência.

Diante dessa conjuntura, a luta de classes merece destaque essencial, posto que os direitos ora retirados, foram, afinal, conquistados por meio do desenvolvimento dessas árduas lutas, que sempre foram imprescindíveis para a garantia de direitos em nosso país. As medidas que implementam direitos são decorrentes das lutas exercidas por diversos trabalhadores; sendo assim, ainda prevalecem como o ponto de partida para enfrentamento do retrocesso atual.

[...] Para as classes subalternas trata-se de buscar ser direção de todos os dominados e apresentar-se praticamente, como projeto que permite criar o horizonte ideológico, no qual as demais classes se moverão ou poderão vir a mover-se. Horizonte que desorganiza, inviabiliza, ou pelo menos o tenta, os projetos das demais classes. Desorganiza ativa ou passivamente: ativamente ao sobrepor com o seu os outros projetos e assim descaracterizálos; passivamente pela repressão pura e simples aos demais projetos. Horizonte que é a estruturação do campo das lutas, das alianças, do permitido e do interdito. A hegemonia é a racionalidade da classe que se faz história e que obriga as demais classes a se pensar nessa história que não é a delas (DIAS, 2006, p.63).

È urgente a necessidade das classes subalternas apropriarem-se da direção, mas, de forma organizada e bem planejada. "Os grupos subalternos sofrem sempre a iniciativa dos grupos dominantes, mesmo quando se rebelam e insurgem: só a vitória "permanente" rompe, e não imediatamente, a subordinação." (GRAMSCI, 2002, p. 135). Neste sentido, ao analisar a emergência do estabelecimento da luta de classes e formas de resistência, a categoria de reforma intelectual e moral das massas de Antônio Gramsci deve ser levado em consideração, visto que no momento contemporâneo torna-se de grande relevância.

Enquanto isso, a população trabalhadora, que lutou e luta constantemente para garantir 0 acesso aos meios de subsistência, que é responsável por prover toda a riqueza socialmente produzida, acompanha quase que imobilizada a eliminação de seus direitos, com lutas carentes de densidade, pois, verifica-se uma conjuntura acrítica, de alienação e desesperança; a classe trabalhadora vive um 
momento preocupante de grande "passividade". E diante desta conjuntura a reforma moral e intelectual das massas torna-se ponto de partida, visto que:

Dessa situação de subalternidade pode-se emergir quando se assume a consciência do significado do próprio operar, da efetiva posição de classe, da natureza das hierarquias sociais e políticas. Quando se elabora, enfim, uma nova concepção de política, de Estado, de sociedade, superando a concepção de mundo imposta mecanicamente a partir do ambiente externo, da sociedade oficial de modo passivo, substituindo a "espontaneidade" pela "direção consciente", por uma visão de mundo coerente, critica e renovada. (SIMIONATTO, 2009, p.48).

Desse modo, a realidade atual é marcada por visões simplistas e acríticas. Os subalternos, de fato, não conseguem estabelecer uma análise da totalidade que os aliena, e mistifica relações sociais. Assim, a busca pelo conhecimento critico e propositivo é o caminho a ser seguido, para que sejam estabelecidas concepções de mundo, mais aguçadas, críticas e analíticas.

Os dominantes aparentemente triufam em cima dos dominados. Na classe desprovida de riqueza monetária, prevalece ainda pobreza de luta, de esperança e de união. Alguns preferem acreditar apenas na figura de um novo candidato e aguardar as eleições, outros afirmam não crer num futuro melhor, há os que culpabilizam eleições anteriores, os que incitam ódio em defesa de determinados candidatos de cunho conservador; fala-se até em intervenção militar. Mas, o poder da luta de classe é deixado de lado, a divisão da classe trabalhadora não é discutida, e o povo segue confiando em partido. E para alterar tal contexto, é imprescindível uma reforma intelectual e moral. ${ }^{8}$

Nesse sentido, a análise das políticas sociais deve ser realizada através de uma visão de totalidade desde o seu surgimento até os dias atuais, destacando a contradição que a rodeia devido a interesses antagônicos entre as classes sociais e a atuação do Estado enquanto instituição detentora de poder que pode contribuir para a classe trabalhadora ou burguesa, ora atendendo necessidades sociais e, respectivamente, mantendo o acúmulo capitalista e, principalmente, enfatizando as lutas revolucionárias desencadeadas pelos trabalhadores.

\section{CONCLUSÃO}

A realidade contemporânea é preocupante, pois diante de uma crise orgânica não é possível supor os caminhos políticos e econômicos do país. Emergem neste contexto, sujeitos que incitam ódio, forte onda conservadora que impregna ainda mais na mente dos indivíduos ideias que dificultam a organização das classes subalternas.

Nesse sentido, é visível também, uma crise de conhecimento. Sujeitos que não se apropriam da formação social, política e histórica do país para dela extrair aprendizados concretos, que 
não levam em consideração acontecimentos que marcaram e como marcaram nossa trajetória, como, por exemplo, a ditadura militar, hoje defendida por grupos atrelados ao conservadorismo. A classe dominante ainda vem estabelecendo reformas para fortalecer tal crise de conhecimento, como a medida provisória que reformula o ensino médio, agora Lei 13.415/2017, acarretando maiores fragilidades na educação brasileira. Convergimos com Tonet (2016) acerca de como a educação pode contribuir para a construção de uma nova sociedade, porém com a "consciência da própria historicidade" processo já enfatizado por Gramsci (2004), e, disso, os capitalistas já têm plena convicção.

Nesse contexto, são intensificadas políticas de cunho compensatório, focalistas e assistencialistas. $O$ intuito é aparentar estabelecer direitos por meio de medidas que não resolvem e/ ou amenizam as expressões da questão social, que assim, tendem a agudizar-se, prevalecendo, assim, o retorno à culpalbilização das vitimas, repressão e caridade.

Num país cada vez mais dependente, o retrocesso não é apenas de direitos. É retrocesso de conhecimento, de posição social frente às regressões estabelecidas, e, principalmente, de lutas. Portanto, o ponto de partida é a reforma intelectual e moral das massas. Para além do aprofundamento no marxismo e no pensamento gramsciano, da luta contra as reformas implantadas, é imprescindível, voltar-se para a análise da história do Brasil, que ainda renova processos históricos e esconde descobertas valiosas para estabelecimento de uma visão de mundo crítica e revolucionária.

Portanto, há possibilidades de restabelecer as lutas; para tanto, exige-se uma apropriação sobre particularidades da formação social, cultural, política, econômica e ideológica brasileira. É imprescindível a construção de uma maturidade intelectual, um caminho supostamente longo, mas não impossível.

\section{REFERÊNCIAS}

BEHRING, E.R; BOSCHETTI, I. A política Social: fundamentos e História. 8 ed. São Paulo: Cortez, 2011.

BIANCHI, A. Revolução passiva e crise de hegemonia no Brasil contemporâneo. Revista Outubro, n.28, abril de 2017.

COSTA, F.S. M. Trabalho e proteção social na acumulação flexível: individualização e gerenciamento do risco social. In: Revista de Políticas Públicas/UFMA, v. 21, n.2, São Luis, EDUFMA, 2017.

DIAS, E.F. Política brasileira: embate de projetos hegemônicos. São Paulo: Editora Instituto José Luís e Rosa Sundermann, 2006, 240 p.23 cm (Série Polêmicas, 4). 
GONÇALVES, R. Redução da desigualdade da renda no governo Lula: análise comparativa. In: SALVADOR, E. et al. (orgs.). Financeirização, fundo público e política social. São Paulo: Cortez, 2012, p. 285-317.

GRAMSCl, A. Cadernos do cárcere. Tradução de Carlos Nelson Coutinho com a colaboração de Luiz Sergio Henriques e Marco Aurélio Nogueira. 3 ed. Rio de Janeiro: Editora Civilização Brasileira, 2007. v.3.

Cadernos do cárcere. Tradução de Carlos Nelson Coutinho com a colaboração de Luiz Sergio Henriques e Marco Aurélio Nogueira. Rio de Janeiro: Editora Civilização Brasileira, 2002. v.5.

Cadernos do cárcere. Tradução de Carlos Nelson Coutinho com a colaboração de Luiz Sergio Henriques e Marco Aurélio Nogueira. 3 ed Rio de Janeiro: Editora Civilização Brasileira, 2004. v.1.

GUIOT, A.P. Dominação burguesa no Brasil: estado e sociedade civil no Conselho de Desenvolvimento Econômico e Social (CDES) entre 2010 e 2013. Tese (Doutorado) - Universidade Federal do Fluminense, Departamento de História, 2015.

IANNI, O. Teorias da globalização. Rio de Janeiro, Civilização Brasileira, 1996.

IASI, M. Democaria de cooptação e o apassivamento da classe trabalhadora. In: SALVADOR, E. et al. (orgs.). Financeirização, fundo público e política social. São Paulo: Cortez, 2012, p.285-317.

LIGUORI, G; VOZA, P. (Orgs). Dicionário Gramsciano (1926-1937). 1 ed. São Paulo: Boitempo, 2017. 831p. ISBN: 978-85-7559-535-6.

MARX, K. Miséria da Filosofia: Resposta à Filosofia da Miséria do Sr. Proudhon. São Paulo: Livraria Editora Ciências Humanas, 1982.

OLIVEIRA, F. Hegemonia às avessas. In: Oliveira, F.; Braga, R.; Rizeck, C. Hegemonia às avessas: economia, política e cultura na era da servidão financeira. São Paulo: Boitempo, 2010.

A economia da dependência imperfeita. Rio de Janeiro, Edições Graal. 4 ed.1984.

SIMIONATTO, I. Classes subalternas, lutas de classe e hegemonia: uma abordagem gramsciana. Revista Katálysis. v.12, n.1, p. 41-49, jan./jun.2009.

TONET, I. Educação contra o capital. 3 ed. Maceió: Coletivo Veredas, 2016.

\section{Notas}

${ }^{1}$ A palavra passividade será destacada, visto que, não se pode desconsiderar a importância das expressões de resistência e luta exercida por determinados grupos sociais, em diferentes contextos, lutas estas carentes de estratégias para serem desenvolvidas com maior densidade.

${ }^{2}$ Gonçalves (2012) analisa que em relação ao escopo das políticas de redução de desigualdade, na América Latina os fatores comuns talvez sejam "imperativo da governabilidade" (determinante) que decorre da legitimidade do Estado e da 
A PASSIVIDADE ESTRATEGICAMENTE CONSTRUÍDA: o consenso contemporâneo a partir de categorias gramscianas

estabilidade política e a redução da vulnerabilidade externa conjuntural (condicionante). Ainda de acordo com o autor essa hipótese deve ser investigada.

${ }^{3} \mathrm{~A}$ tese de Andre Guiot (2015) é reveladora desta realidade, o autor, ao analisar o CDES demonstrou como este órgão é palco de forças sociais no interior do Estado, com intuito de ampliar a acumulação capitalista, com feição distributiva oriunda da ressignificação rebaixada das reivindicações populares.

${ }^{4} \mathrm{O}$ autor Bianchi (2017) ao abordar sobre tal realidade na era Lula, destaca a categoria revolução passiva para sua explicação, pois, tal processo combinava ambas as formas de organização. Eram ativas na capacidade de incorporar à gestão estatal quadros provenientes do movimento sindical, que se transformavam em gestores estatais e em gestores de fundo de pensão. Mas, no que diz respeito ao conjunto das classes subalternas, essa incorporação política ao Estado, essa ampliação da base do Estado, ocorreu por meio da conformação de um consenso de tipo passivo. Ou seja, por meio de certas políticas públicas, particularmente políticas assistenciais.

5 "A "passividade política" das grandes massas, por sua vez, é uma forma de atividade enquanto é uma busca de solução a uma crise de consenso do Estado" (LIGUORI; VOZA, 2017, p.143).

${ }_{6}^{6}$ Para Dias (2006, p.32) Gramsci elabora sua teoria do Estado como unidade articulada de consenso e coerção, pensa-0 como produtor da organização/desorganização da totalidade da sociedade [...].

${ }^{7}$ Segundo, Oliveira (1984, p.122), o que a "ciência oficial" ainda não entendeu é que a estabilidade das classes dominantes depende, fundamentalmente, do tipo de relação que mantêm com as classes dominadas.

8 Gramsci (2004, p.104), já alertava que autoconsciência critica significa, histórica e politicamente, criação de uma elite de intelectuais. Mas, tal processo de acordo com o autor é lento, dificil, cheio de contradições, de avanços e de recuos, de debandadas e reagrupamentos; [...]. 